\title{
Coordenação do cuidado às pessoas que vivem com HIV no sistema prisional
}

\author{
Coordination of care for people living with HIV in the prison system \\ Coordinación del cuidado a las personas que viven con el VIH en el sistema penitenciario \\ Aline Cristina Gonçalves Andrade Cadamuro' ${ }^{1}$ io https://orcid.org/0000-0002-1002-4212 \\ Rubia Laine de Paula Andrade ${ }^{2}$ io https://orcid.org/0000-0001-5843-1733 \\ Livia Maria Lopes ${ }^{3}$ in nttps://orcid.org/0000-0002-5775-305x \\ Lis Aparecida de Souza Neves ${ }^{1}$ io https://orcid.org/0000-0001-5255-2649 \\ Erika Aparecida Catoia ${ }^{4}$ id https://orcid.org/0000-0003-1687-5007 \\ Aline Aparecida Monroe ${ }^{2}$ io https://orcid.org/0000-0003-4073-2735
}

\section{Como citar:}

Cadamuro AC, Andrade RL, Lopes LM, Neves LA, Catoia EA, Monroe AA. Coordenação do cuidado às pessoas que vivem com HIV no sistema prisional. Acta Paul Enferm. 2020;33:eAPE20190267.

DOI

http://dx.doi.org/10.37689/actaape/2020A002676

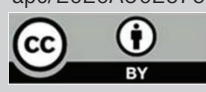

Descritores

da imunodeficiência adquirida; Pesquisa sobre serviços de saúde: Assistência integral à saúde

Keywords

Prisions: HIV: Acquired immunodeficiency syndrome; Health service research; Comprehensive health care

Descriptores

Prisiones; VIH: Síndrome de inmunodeficiencia adquirida Investigación sobre servicios de salud; Atención integral de salud

\section{Submetido \\ 12 de Setembro de 2019 \\ Aceito \\ 12 de Março de 2020}

\section{Autor correspondente}

Aline Aparecida Monroe E-mail: amonroe@eerp.usp.br

\section{Resumo}

Objetivo: Analisar a coordenação do cuidado às pessoas que vivem com HIV, segundo unidade prisional.

Métodos: Estudo transversal, realizado em seis unidades prisionais do Estado de São Paulo. Entrevistaram-se 85 detentos vivendo com HIV e seis diretores técnicos. Indicadores de coordenação foram criados a partir de perguntas com escala de 1 a 5 , classificando-os em satisfatórios $(>3,5$ a 5,0), regulares $(>2,5$ a 3,5$)$ e insatisfatórios (1,0 a 2,5). Utilizou-se ANOVA e Kruskal Wallis.

Resultados: A coordenação foi classificada como insatisfatória (média 2,49). Indicadores insatisfatórios: "Questionar efeitos colaterais da terapia antirretroviral (TARV)"; "Questionar dificuldades na tomada da TARV"; "Observar tomada da TARV"; "Solicitar fracos/embalagens da TARV para monitorar a ingesta medicamentosa"; "Pedir explicações quanto ao uso da TARV"; "Questionar condições de acondicionamento da TARV na cela"; "Informar e discutir resultados T-CD4+ e carga viral"; "Informar agendamento da consulta no serviço de referência em HIV" e "Levar para atendimento em outras especialidades médicas". Obtiveram classificação regular. "Levar para atendimento médico de urgência quando necessário" e "Não perder consulta no serviço de referência em HIV". "Questionar sobre a regularidade no uso da TARV" foi o único indicador pior avaliado na comparação entre as unidades prisionais estudadas $(p<0,05)$.

Conclusão: 0 desempenho das unidades prisionais não difere em relação à grande parte dos indicadores de coordenação estudados, indicando que todas precisam melhorar o desempenho no que diz respeito ao desenvolvimento de ações de monitoramento do uso da TARV, informar e discutir resultados dos exames com os detentos e levar para atendimento fora da unidade prisional.

\section{Abstract}

Objective: To analyze the care coordination for people living with HIV according to the prison unit.

Methods: Cross-sectional study conducted in six prison units in the state of São Paulo. Eighty-five inmates living with HIV and six technical directors were interviewed. Coordination indicators were created from questions with a $1-5$ scale and classified as satisfactory (>3.5 to 5.0), regular (>2.5 to 3.5) and unsatisfactory (1.0 to 2.5). ANOVA and Kruskal Wallis were used.

Results: The coordination was classified as unsatisfactory (mean 2.49). Unsatisfactory indicators: "Questioning side effects of antiretroviral therapy (ART)"; "Questioning the difficulties in ART intake"; "Observing ART intake"; "Requesting ART bottles/packages to monitor medication intake"; "Asking for explanations regarding the use of ART"; "Questioning the storage conditions of ART in the prison cell"; "Informing and discussing T-CD4 + and

Prefeitura Municipal de Ribeirão Preto, Ribeirão Preto, SP, Brasil.

¿Escola de Enfermagem de Ribeirão Preto, Universidade de São Paulo, Ribeirão Preto, SP, Brasi

${ }^{3}$ Centro Universitário de Franca Uni-FACEF, Franca, SP, Brasil.

${ }^{4}$ Secretária de Administração Penitenciária, Ribeirão Preto, SP, Brasil.

Conflitos de interesse: Manuscrito extraído da tese "Coordenação do cuidado durante a assistência prestada às pessoas privadas de liberdade que vivem com HIV", apresentada em 2019 ao Programa de Pós-graduação Enfermagem em Saúde Pública da Escola de Enfermagem de Ribeirão Preto, Universidade de São Paulo. 
viral loading results"; "Informing the scheduling of consultation at the HIV reference service" and "Take to care for other medical specialties". The following obtained regular classification: "Take to emergency medical care when needed" and "Not missing an appointment at the HIV reference service". "Questioning the regularity of the use of ART" was the single worst indicator evaluated in the comparison between the prison units studied $(p<0.05)$.

Conclusion: The performance of prison units does not differ in relation to most coordination indicators studied, which shows the need for improving the performance with regard to the development of actions to monitor the use of ART, inform and discuss test results with inmates and take them to care outside the prison unit.

\section{Resumen}

Objetivo: Analizar la coordinación del cuidado a las personas que viven con el VIH, según unidad penitenciaria.

Métodos: Estudio transversal realizado en seis unidades penitenciarias del estado de São Paulo. Se realizó entrevista a 85 presos que viven con el VIH y seis directores técnicos. Fueron creados indicadores de coordinación a partir de preguntas con escala de 1 a 5 y se clasificaron en satisfactorios (>3,5 a 5,0), regulares $(>2,5$ a 3,5) e insatisfactorios $(1,0$ a 2,5). Se utilizó ANOVA y Kruskal Wallis.

Resultados: La coordinación fue clasificada como insatisfactoria (promedio 2,49). Indicadores insatisfactorios: "Preguntar sobre efectos secundarios del tratamiento antirretroviral (TARV)", "Preguntar sobre dificultades en la toma del TARV", "Observar toma del TARV", "Solicitar frascos/envases del TARV para monitorear la ingesta de medicamentos", "Pedir explicaciones sobre el uso del TARV", "Preguntar sobre condiciones de almacenaje del TARV en la celda", "Informar y discutir resultados T CD4+ y carga viral", "Informar consultas agendadas en el servicio de referencia en VIH" " "Llevar para recibir atención en otras especialidades médicas". Obtuvieron clasificación regular los indicadores: "Llevar para recibir atención médica de urgencia cuando es necesario" y "No perder el turno en el servicio de referencia en VIH". "Preguntar sobre la regularidad de uso del TARV" fue el único indicador peor evaluado en la comparación entre las unidades penitenciarias estudiadas $(p<0,05)$.

Conclusión: El desempeño de las unidades penitenciarias no difiere con relación a la mayoría de los indicadores de coordinación estudiados, lo que indica que todas necesitan mejorar el desempeño respecto al desarrollo de acciones de monitoreo del uso del TARV, informar y discutir resultados de los análisis con los presos y llevarlos para recibir atención fuera de la unidad penitenciaria.

\section{Introdução}

As pessoas privadas de liberdade (PPL), juntamente com outros grupos populacionais, são consideradas populaçóes-chave e prioritárias para o cuidado em saúde devido ao maior risco de infecçáo pelo HIV/ aids. ${ }^{(1)}$ Em 2017, a Organização Mundial da Saúde (OMS) destacou que a incidência do HIV entre as populaçóes-chave continua a aumentar e que entre $40 \%$ e $50 \%$ das novas infecçóes pelo vírus ocorrem nestas populaçóes e seus parceiros. ${ }^{(1)}$

Embora amparados por lei dentro do rol de açôes e serviços de saúde do Sistema Único de Saúde (SUS), a população prisional representa um segmento amplamente exposto a condiçóes indignas de confinamento, tornando-as vulneráveis tanto no âmbito programático como individual à infecçôes e/ou adoecimentos. Associados a essas condiçóes, tem-se o compartilhamento de insumos para uso de drogas, tatuagens, sexo desprotegido e práticas homossexuais, ${ }^{(2)}$ que expóe os sujeitos à infecção pelo HIV. ${ }^{(3)}$

Nesse contexto, foram criados os Núcleos de Atendimento à Saúde (NAS), os quais representam serviços de Atenção Primária à Saúde (APS) no sistema prisional, tornando-se porta de entrada das Redes de Atençáo (RAS) e um local de acompanhamento longitudinal, devendo promover integração de açóes e articulação com os demais pontos de atenção à saú- de do SUS, em consonância com as necessidades e demandas dessa das PPL. ${ }^{(4)}$ Além disso, para assegurar a assistência em saúde aos detentos, foi instituída a Política Nacional de Atenção Integral à Saúde das PPL (PNAISP), garantindo açóes de promoçấo, prevenção e de manejo de agravos já instalados e recorrentes, com destaque para o HIV. ${ }^{(5)}$

Em função disso, entende-se que a execução do atributo da APS, coordenaçáo do cuidado, é necessário, uma vez que pressupóe garantir a continuidade assistencial em articulação com os membros e recursos dentro do próprio serviço (integração horizontal) ou com outros pontos de atenção da RAS (integração vertical). ${ }^{(4,0)} \mathrm{Tal}$ entendimento é reforçado em função da segmentação e fragmentação do cuidado configurar-se como desafios para o acompanhamento e continuidade da atenção no que se refere às condiçóes crônicas, ${ }^{(7)}$ como o HIV.

Frente ao exposto, este estudo objetivou analisar a coordenação do cuidado prestado no âmbito prisional às pessoas vivendo com HIV, segundo unidade prisional, partindo-se da hipótese de que existe diferença entre as mesmas em relação ao cuidado prestado.

\section{Métodos}

Estudo transversal, com abordagem quantitativa, que compreende parte de um estudo maior. $\mathrm{O}$ cenário de 
investigação foi composto por seis unidades prisionais da região de Ribeirão Preto, que abriga detentos aguardando julgamento em centros de detenção provisórias (CDP), como aqueles que cumprem pena em penitenciarias. Como forma de resguardar a privacidade das equipes, as UP foram nomeadas segundo as siglas: UPA; UP-B; UP-C; UP-D; CDP-E; e CDP-F. As mesmas estavam ocupadas, em 2015, por 1.767, 1.671 . 1.922, 507, 882, 1.091 detentos, respectivamente.

Convém destacar que o acompanhamento e seguimento especializado da PPL vivendo com HIV no local estudado era realizado em serviços especializados da rede pública de saúde. Em casos de intercorrências, os atendimentos eram prestados por duas Unidades de Pronto Atendimento.

A populaçáo do estudo foi constituída por todas as PPL que viviam com HIV/aids no sistema prisional da região de Ribeirão Preto. Utilizou-se como critério de inclusão os indivíduos que estavam custodiadas por mais de seis meses onde a coleta dos dados foi realizada.

Realizou-se ainda entrevista com todos os seis diretores técnicos de saúde das unidades prisionais que fizeram parte do estudo. Tanto para as PPL quanto para os diretores de saúde, definiu-se como critério de exclusão a recusa em participar do estudo. Importante ressaltar que nenhum deles se recusou a participar do estudo.

Realizada de agosto a novembro de 2015 , utilizou instrumento de coleta de dados do projeto maior, o qual foi elaborado com base nas Recomendaçóes do Plano Nacional para TARV em adultos infectados pelo HIV; ${ }^{(8)}$ no Protocolo de Atenção Básica da Saúde nas UP do Estado de São Paulo; ${ }^{(9)}$ e no Primary Care Assessment Tool (PCAT). ${ }^{(10)} \mathrm{O}$ instrumento elaborado foi submetido a validação de conteúdo por especialistas e teste piloto para análise de conteúdo e semântica, sendo posteriormente aplicado às PPL que viviam com HIV e disponibilizado na tese de doutorado (https://teses.usp.br/teses/disponiveis/22/22133/tde-09082019-111646/publico/ALINECRISTINAGONCALVESANDRADE. pdf) cujo presente artigo foi extraído. A versão final do mesmo contemplava 44 variáveis distribuídas em seis seções: I- Dados sociodemográficos; II- Prática sexual; III- Dados clínicos e de acompanhamento;
IV- Percurso no sistema prisional; V - Elenco de ações e serviços ofertados pelas UP às PPL com HIV/ aids; e VI -Coordenação e integração das açóes e serviços de saúde para assistência às PPL com HIV/aids. Para as entrevistas realizadas com os diretores técnicos de saúde, utilizou-se um questionário estruturado específico que compreendeu um "Roteiro para caracterização das Unidades Prisionais", com informaçóes sobre ambiente, estrutura e rotinas de trabalho.

Para este estudo, foram utilizadas variáveis que reportam à avaliação da coordenação do cuidado relacionadas às seçôes III e VI do instrumento de coleta de dados, bem como variáveis pertencentes aos componentes de estrutura e rotinas de trabalho do roteiro de caracterização das UP. As variáveis foram agrupadas segundo as dimensôes da coordenação do cuidado: ${ }^{(11)}$ capacidade das unidades de saúde prisionais na assistência prestada às PPL que vivem com HIV; estrutura administrativa e organizacional; integração entre equipes e serviços de saúde; continuidade informacional.

Para análise dos dados, foram utilizadas técnicas descritivas e construídos indicadores pertinentes às dimensôes "integração horizontal", "integração vertical" e "continuidade informacional". Tais indicadores correspondiam ao valor médio das respostas para cada variável com escala Likert de resposta (de 1 a 5), os quais foram dispostos em box plot, com respectivos intervalos de confiança. Calculou-se também o indicador composto para a coordenação do cuidado. Estes foram classificados em satisfatórios $(>3,5$ a 5,0), regulares $(>2,5$ a 3,5) e insatisfatórios $(1,0$ a 2,5$)$.

Posteriormente, a análise de variância (ANOVA) com teste de Tukey foi utilizada para comparar o desempenho das diferentes UP em relação à coordenação do cuidado. Esse teste foi realizado quando atendidos os pressupostos de homocedasticidade pelo teste Levene. A normalidade não foi testada, uma vez que a populaçáo estudada possuía um $\mathrm{n}$ maior que 30. Quando houve violação dos critérios para o uso da ANOVA, utilizou-se o teste de Kruskall-Wallis e o teste de comparação múltipla. $\mathrm{O}$ nível de significância estatística adotado em todos os testes foi de 5\%.

O presente estudo foi aprovado pelo Comitê de Ética em Pesquisa da instituição responsável, conforme Resolução CNS - pesquisa com seres humanos 466/12 e parecer de aprovação 013/2017. 


\section{Resultados}

No período de coleta de dados, foram identificados 102 detentos com diagnóstico de HIV nas seis UP. Desses, dez não atendiam ao critério de inclusão, cinco recusaram participar do estudo e dois estavam ausentes na unidade, resultando em 85 participantes do estudo.

Em relação ao acompanhamento clínico das PPL que viviam com HIV, verificou-se que 43 (50,6\%) sujeitos receberam o diagnóstico da infecçâo no sistema prisional; $72(84,7 \%)$ estavam em acompanhamento médico; 67 (78,8\%) faziam o uso de terapia antirretroviral (TARV); 13 (15,3\%) interromperam acompanhamento médico em algum momento. No atual encarceramento, $18(21,2 \%)$ informaram internação hospitalar devido ao HIV/aids e 23 (27,1\%) ocorrência de tuberculose (Tabela 1).

Tabela 1. Distribuição de frequência dos dados de acompanhamento clínico das pessoas privadas de liberdade que viviam com HIV nas Unidades Prisionais de uma região de saúde do Estado de São Paulo

\begin{tabular}{llc}
\hline Acompanhamento clínico do HIV & & PVH (N=85) \\
\hline Diagnóstico realizado no sistema prisional & Sim & (\%) \\
\hline Realiza acompanhamento médico do HIV & Não & $43(50,6)$ \\
Uso de TARV & Sim & $42(49,4)$ \\
Interrupção do acompanhamento medico & Sim & $72(84,7)$ \\
& Não & $13(15,3)$ \\
Internação devido HIV/aids & Sim & $67(78,8)$ \\
Doenças relacionadas ao HIV no último & Não & $18(21,2)$ \\
encarceramento* & Sim & $13(15,3)$ \\
& Não & $72(84,7)$ \\
& Tuberculose & $18(21,2)$ \\
& Pneumonia & $67(78,8)$ \\
& Herpes Zoster & $14(27,1)$ \\
& Candidíase Oral & $8(16,5)$ \\
& Sarcoma de Kaposi & $3(3,4,5)$ \\
& Toxoplasmose & $3(3,5)$ \\
& Criptococose & $2(2,4)$ \\
& Citomegalovírus & - \\
\hline
\end{tabular}

*Mais de uma alternativa de resposta a essas variáveis era possível, por isso o percentual de respostas a essas perguntas ultrapassa os $100 \%$.

A PA dispunha de 14 profissionais no momento da coleta de dados, a PB 17, a PC 20, a PD 16, o CDP-E 14 e o CDP-F 11. Quanto a composição de equipe multiprofissional dentro das $\mathrm{UP}$, a PB, a PC e a PD contavam com, pelo menos, sete profissionais de diferentes categorias (médico, enfermeiro, auxiliar/técnico de enfermagem, cirurgião dentista, assistente social, psicólogo e agente penitenciário de saúde). Desses profissionais, a PA e os CDP-D não contavam com médico e o $\mathrm{CDP}-\mathrm{E}$ não contava com médico e nem com cirurgião dentista. $\mathrm{O}$ atendimento às demandas de saúde era realizado, predominantemente, em período integral (83,0\%).

Em relação ao indicador composto geral da coordenação do cuidado durante a assistência prestada às PPL vivendo com HIV nas UP, obteve-se uma média de 2,49 $( \pm 1,82)$, configurando uma classificação insatisfatória.

Quanto à integração horizontal, obtiveram resultados satisfatórios os indicadores: "Não atrasar na entrega dos medicamentos antirretrovirais (ARV)"; "realização de coleta de sangue na UP”, "orientaçôes quanto ao preparo para a coleta de sangue para a realização de exames". Já o indicador "Questionar sobre a regularidade do uso dos medicamentos ARV” foi classificado como regular. Os nove demais indicadores foram considerados insatisfatórios, conforme figura 1.

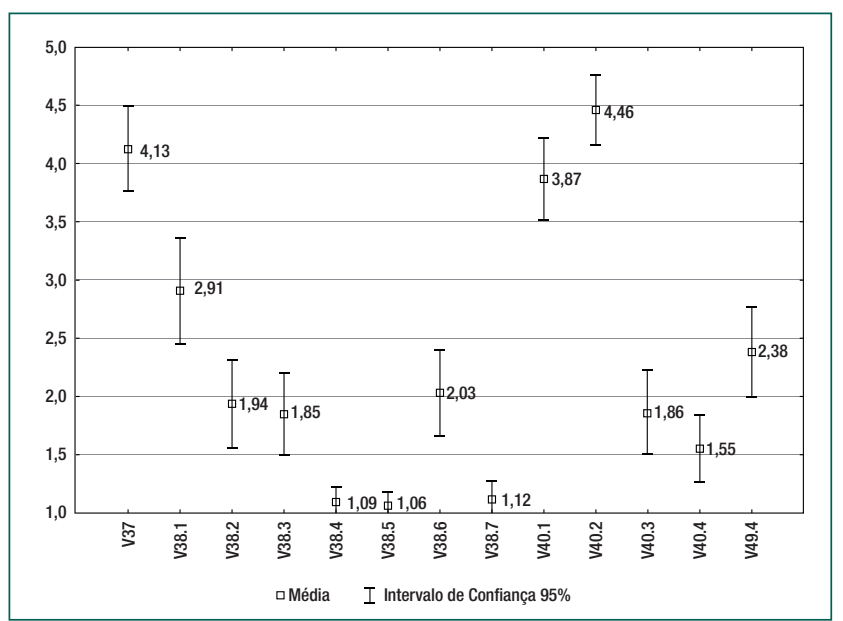

V37- Não atrasa entrega dos medicamentos ARV; V38.1-Questiona regularidade do uso dos medicamentos ARV; V38.2-Questiona efeitos colaterais durante 0 uso TARV; V38.3-Questiona dificuldades na tomada dos medicamentos da TARV; V38.4-Observa a tomada da medicação (TARV); V38.5-Solicita fracos/ embalagens vazias da TARV para monitoramento da tomada da medicação; V38.6- Pede para explicar como a TARV está sendo tomada; V38.7-Questiona condições do local de acondicionamento da TARV na cela de convívio; V40.1Realiza coleta de sangue para exames CD4 e Carga Viral na UP; V40.2-Informa os cuidados preparatórios para a coleta de exames para o controle do HIV; V40.3-Informa os resultados T-CD4+ e carga viral; V40.4-Discute os resultados dos exames. V39.4-Informa o agendamento da consulta com o médico serviço de assistência especializada.

Figura 1. Médias e intervalos de confiança das variáveis da dimensão integração de ações e serviços de saúde dentro das UP (integração horizontal) durante a assistência prestada às pessoas que viviam com HIV nas Unidades Prisionais de uma região de saúde do Estado de São Paulo 
Tabela 2. Indicadores relacionados à coordenação do cuidado em HIV/aids entre as Unidades Prisionais de uma região de saúde do Estado de São Paulo

\begin{tabular}{|c|c|c|c|c|c|c|c|}
\hline Variáveis & $\begin{array}{c}\text { UP-A } \\
\text { Média } \pm \text { DP }\end{array}$ & $\begin{array}{c}\text { UP-B } \\
\text { Média } \pm \text { DP }\end{array}$ & $\begin{array}{c}\text { UP-C } \\
\text { Média } \pm \text { DP }\end{array}$ & $\begin{array}{c}\text { UP-D } \\
\text { Média } \pm \text { DP }\end{array}$ & $\begin{array}{c}\text { CDP-E } \\
\text { Média } \pm \text { DP }\end{array}$ & $\begin{array}{c}\text { CDP-F } \\
\text { Média } \pm \text { DP }\end{array}$ & $p$-value \\
\hline Atrasam a entrega dos medicamentos ARV & $4,33 \pm 1,30$ & $3,73 \pm 1,70$ & $4,69 \pm 0,75$ & $4,29 \pm 1,49$ & $2,00 \pm 1,41$ & 5,00 & $0,1245^{\circ}$ \\
\hline Regularidade da TARV & $3,67 \pm 1,56^{\mathrm{ab}}$ & $2,57 \pm 1,90^{a b}$ & $4,00 \pm 1,71^{\mathrm{a}}$ & $1,71 \pm 1,49^{b}$ & $2,00 \pm 1,41^{\mathrm{ab}}$ & $5,00^{\mathrm{ab}}$ & $0,0067^{\dagger}$ \\
\hline Efeitos colaterais & $2,00 \pm 1,60$ & $1,78 \pm 1,44$ & $2,43 \pm 1,65$ & $1,29 \pm 1,07$ & $3,00 \pm 2,83$ & 5,00 & $0,1031^{*}$ \\
\hline Dificuldades na tomada da medicação - TARV & $2,33 \pm 1,78$ & $1,87 \pm 1,46$ & $2,14 \pm 1,51$ & $1,29 \pm 1,07$ & $1,00 \pm 0,00$ & 1,00 & $0,2969^{*}$ \\
\hline Observam tomar a TARV & $1,17 \pm 0,58$ & $1,17 \pm 0,83$ & $1,00 \pm 0,00$ & $1,00 \pm 0,00$ & $1,00 \pm 0,00$ & 1,00 & $0,9075^{\dagger}$ \\
\hline Pedem embalagem da TARV & $1,33 \pm 1,15$ & $1,00 \pm 0,00$ & $1,00 \pm 0,00$ & $1,00 \pm 0,00$ & $1,00 \pm 0,00$ & 1,00 & $0,4799^{*}$ \\
\hline Pedem para explicar sobre a forma que está tomando os TARV & $2,50 \pm 1,73$ & $1,61 \pm 1,12$ & $2,71 \pm 1,73$ & $1,57 \pm 1,22$ & $1,00 \pm 0,00$ & 5,00 & $0,0545^{*}$ \\
\hline Condições de armazenamento TARV na cela de convívio & $1,17 \pm 0,58$ & $1,17 \pm 0,83$ & $1,00 \pm 0,00$ & $1,14 \pm 0,53$ & $1,00 \pm 0,00$ & 1,00 & $0,9682^{\dagger}$ \\
\hline Levam atendimento de urgência & $4,17 \pm 1,34^{\mathrm{a}}$ & $3,67 \pm 1,63^{\mathrm{a}}$ & $4,65 \pm 1,06^{a}$ & $3,00 \pm 1,85^{\mathrm{a}}$ & $5,00 \pm 0,00^{\mathrm{a}}$ & $3,00 \pm 2,83^{a}$ & $0,0334^{*}$ \\
\hline Realizam coleta de sangue para CD4 e Carga Viral (CV) & $3,83 \pm 1,80$ & $4,45 \pm 1,35$ & $4,78 \pm 0,94$ & $4,38 \pm 1,50$ & $5,00 \pm 0,00$ & 5,00 & $0,4035^{*}$ \\
\hline Informam sobre os cuidados preparatórios para a coleta de exame & $1,33 \pm 1,15^{a}$ & $2,00 \pm 1,72^{\mathrm{a}}$ & $2,76 \pm 1,86^{a}$ & $1,00 \pm 0,00^{\mathrm{a}}$ & $1,00 \pm 0,00^{\mathrm{a}}$ & $5,00^{\mathrm{a}}$ & 0,0032 \\
\hline Informam resultado de exame CD4 e CV & $1,33 \pm 1,15$ & $1,71 \pm 1,51$ & $1,82 \pm 1,42$ & $1,00 \pm 0,00$ & $2,00 \pm 2,00$ & 1,00 & $0,3264^{*}$ \\
\hline Discutem os resultados dos exames & $1,33 \pm 1,15^{\mathrm{a}}$ & $2,71 \pm 1,78^{\mathrm{a}}$ & $3,00 \pm 2,06^{a}$ & $1,43 \pm 0,85^{\mathrm{a}}$ & $4,00 \pm 2,00^{\mathrm{a}}$ & $1,00 \pm 0,00^{\mathrm{a}}$ & $0,0093^{*}$ \\
\hline Levam atendimento especializado & $3,75 \pm 1,49^{a}$ & $2,64 \pm 1,89^{\mathrm{a}}$ & $3,94 \pm 1,60^{\mathrm{a}}$ & $2,00 \pm 1,70^{\mathrm{a}}$ & $3,00 \pm 2,00^{\mathrm{a}}$ & $5,00 \pm 0,00^{\mathrm{a}}$ & $0,0368^{*}$ \\
\hline Não perdem consulta no infectologista & $1,36 \pm 1,21^{\mathrm{a}}$ & $2,31 \pm 1,79^{\mathrm{a}}$ & $3,59 \pm 1,84^{a}$ & $2,00 \pm 1,52^{\mathrm{a}}$ & $3,50 \pm 1,91^{\mathrm{a}}$ & $1,00 \pm 0,00^{\mathrm{a}}$ & $0,0121^{*}$ \\
\hline Informam agendamento da consulta & $3,67 \pm 1,56^{a}$ & $2,76 \pm 1,71^{\mathrm{a}}$ & $4,13 \pm 1,45^{a}$ & $2,57 \pm 1,79^{\mathrm{a}}$ & $4,00 \pm 2,00^{\mathrm{a}}$ & $5,00^{\mathrm{a}}$ & $0,0415^{\dagger}$ \\
\hline Reforçam orientações do infectologista & $2,50 \pm 1,93$ & $2,69 \pm 1,93$ & $3,47 \pm 1,81$ & $2,00 \pm 1,71$ & $2,50 \pm 1,91$ & 5,00 & $0,2676^{\dagger}$ \\
\hline
\end{tabular}

Categorias de respostas: 1 - Nunca; 2 - Quase nunca; 3 - Às vezes; 4 - Quase sempre; 5 - Sempre. ${ }^{*}$ teste kruskal-Wallis; ${ }^{\dagger}$ teste ANOVA; ${ }^{\text {a ou }}$ letras iguais entre as UPs significam que não houve diferença estatisticamente significante para o teste de comparação múltipla; letras diferentes entre as UPs mostram que houve diferença estatisticamente significante

Ainda em relação à integração horizontal, seis (100\%) diretores técnicos de saúde acolhimento à demanda espontânea, testagem anti-HIV, Hepatites e Sífilis e coleta TCD4+/ Carga Viral in loco. Em relação à TARV, cinco $(83,3 \%)$ unidades dispensavam aos detentos mensalmente. Três $(50,0 \%)$ UP informaram o desenvolvimento de estratégias para avaliar a adesão medicamentosa.

Em relação à integração vertical, obtiveram classificação regular: "Levar para atendimento médico de urgência fora da UP na presença de problemas de saúde" (média 3,09) e "Não perder consulta com o infectologista no serviço de assistência especializada" (média 3,23). Foi classificado como insatisfatório o indicador "Levar para atendimento em outras especialidades médicas quando necessário" (média 2,43).

Ainda na integração vertical, cinco $(83,3 \%)$ diretores técnicos de saúde informaram que a discussão de casos com os serviços de referência em HIV ocorria por e-mail e quatro $(66,6 \%)$ por telefone.

No que tange à continuidade informacional, o indicador "Reforçam as orientaçóes dadas pelo médico que acompanha o seu tratamento do HIV" foi classificado como regular (média 2,64). Nesta dimensão, dois $(33,3 \%)$ diretores técnicos de saúde informaram que os agentes penitenciários realizam a interlocução de informaçóes dos procedimentos realizados nos serviços especializados em HIV.

Em relação ao desempenho das diferentes UP, o indicador "Questionam a regularidade no uso da TARV" foi melhor avaliado na UP-C em relação à UP-D. Outros indicadores apresentaram diferença estatisticamente significante para ANOVA e o teste Kruskal-Wallis, no entanto, o mesmo não ocorreu nas análises de comparação múltipla (Tabela 2).

\section{Discussão}

O diagnóstico da infecção pelo HIV foi descrito pelos diretores técnicos de saúde como rotina no momento de admissão do detento no sistema prisional. O empreendimento de açóes para a realização de exames voltados ao diagnóstico do HIV dentro das UP reflete a valorização das diretrizes internacionais para o controle da disseminação do vírus nas prisóes, uma vez que a UNAIDS estabeleceu, para 2020, a promoção da ampliação do diagnóstico da infecção como uma de suas metas precípuas. ${ }^{(12)}$

O diagnóstico representa uma das etapas da cascata do cuidado continuo em HIV e reflete o acesso às ações e serviços de saúde ofertados para a prevenção e o manejo da infecção. Estudos internacionais apontam 
que, após a instituição do diagnóstico, o tratamento do HIV no encarceramento promoveu melhoria significativa nas condiçóes clínicas dos apenados devido à supressão viral e a vinculação ao seguimento terapêutico, ${ }^{(13-16)}$ reforçando a longitudinalidade e continuidade da atenção como componentes prioritários da coordenação da assistência em HIV/aids no sistema prisional.

Entre as comorbidades relacionadas ao HIV identificadas, merece destaque a tuberculose. Estudo desenvolvido na África identificou que, apesar de os reclusos apresentarem status sorológicos dentro da normalidade (T-CD4+ acima de 500 células $/ \mathrm{mm}^{3}$ ), a prevalência de coinfecção TB/HIV foi elevada. ${ }^{(13)}$ Outro fato a ser ressaltado diz respeito à constituiçáo dos detentos enquanto populaçóes-chave/vulneráveis para o desenvolvimento tanto do HIV, quanto da TB. ${ }^{(17)}$ Isso ocorre em virtude dos comportamentos de risco adotados por essa população, ${ }^{(18)}$ bem como das condiçóes das unidades prisionais, com superlotação e baixa ventilação, dentre outros. ${ }^{(17)}$

Quanto à integração horizontal, três indicadores dessa dimensão foram avaliados de forma satisfatória e apontam as responsabilidades assumidas pelas equipes de saúde das UP no que tange à dispensação da TARV aos detentos e à coleta de exames para o acompanhamento clínico dos sujeitos. A operacionalização destas açóes no âmbito prisional pressupóe uma assistência à saúde compartilhada, em articulação com serviços especializados em HIV, unidades dispensadoras de medicamentos e rede laboratorial.

As ações de vigilância e monitoramento do uso da TARV apresentaram avaliação insatisfatória, exceto o indicador "Questionar a regularidade no uso da TARV”, classificado como regular. Estes resultados sugerem que tais atividades são pouco frequentes na dinâmica do cuidado prestado nas UP, apesar dos esforços para a entrega regular da TARV aos detentos, configurando uma possível fragmentação assistencial e uma transferência de responsabilidade aos detentos em relação ao autocuidado e adesão terapêutica. $\mathrm{O}$ autocuidado deve fomentar a autonomia dos usuários, tendo a equipe como retaguarda e fonte usual de apoio, incentivo e motivação. ${ }^{(4)}$

Ainda em relação às açóes de monitoramento do uso da TARV, três UP informaram a supervisão da tomada dos ARV quando os detentos procuravam as enfermarias, realização de vistorias mensais nas celas e questionamento aos sujeitos. Vale mencionar que em função das limitaçóes estruturais do sistema prisional brasileiro, tais açôes possuem características pontuais e assistemáticas na dinâmica do cuidado prestado, podendo passar despercebidas pelos detentos.

Elementos avaliados de forma insatisfatória e que poderiam contribuir no processo de construção do autocuidado apoiado pelas equipes das UP seriam a divulgação e a discussão de resultados de exames de T-CD4+ e carga viral com os detentos, pois permitiriam sensibilizar e empoderar os sujeitos em relação às suas condições clínicas e necessidade de aderir ao tratamento.

Em relação à composição das equipes, identificou-se que $50 \%$ das UP possuíam sete profissionais de diferentes categorias, contudo, em relação à figura do médico, no momento da coleta de dados, 50\% das UP não dispunham deste profissional. A incompletude no quadro de recursos humanos interfere na atuação e resolutividade das UP enquanto ponto de APS e está em descompasso com o que é preconizado pela PNAISP. ${ }^{(5)}$ Tal situação, somada à superlotação das UP estudadas, constituem elementos que podem gerar sobrecarga de trabalho para as equipes e, consequentemente, refletir na assistência prestada. Dessa forma, as unidades precisam fazer articulação com outros pontos de atenção, necessitando deslocamento dos detentos para fora da UP com mobilização de agentes penitenciários, viatura e escolta policial.

$\mathrm{Na}$ integração vertical, foram identificadas fragilidades na articulaçáo com os demais pontos de atenção e reitera as dificuldades enfrentadas na logística requerida nos deslocamentos externos às UP, como foi apontado também em outro estudo. ${ }^{(19)} \mathrm{Na}$ integração entre UP e serviços da rede de atenção, a assistência à saúde implica na cooperação de diversos atores para a coordenação e continuidade do cuidado $^{(20)}$ e na comunicação entre equipes de saúde e de justiça/segurança. Os diretores de técnicos de saúde sinalizaram debilidades na integração entre tais equipes, o que compromete a integralidade e a resolutividade do cuidado prestado, de acordo com as necessidades e demandas de saúde das PPL.

$\mathrm{O}$ indicador "Levar para atendimento em outras especialidades médicas" foi avaliado como insatisfatório em função de três UP estarem localizadas em 
um município de pequeno porte, cuja grade de referência para pontos de atenção secundários e terciários envolve a condução a outros municípios. Para o acesso exige disponibilidade de vagas, de agendamento e a integração multiprofissional entre serviços de saúde e de segurança pública. Nesta direção, identifica-se a importância de avaliar a RAS disponível no SUS dos municípios no momento da construção de novas UP visando a garantia do acesso à saúde das PPL. ${ }^{(19)}$

Outros entraves apontados em relação aos encaminhamentos compreendem as falhas na comunicação formal quando as PPL são referenciadas para serviços de saúde externos às UP em situaçóes de agudização do HIV. ${ }^{(21,22)}$ Importante ressaltar o papel articulador das UP no processo de coordenação do cuidado, visando a gestão compartilhada dos atendimentos em saúde, efetivada por mecanismos formais e informais de comunicação, de modo que o compartilhamento de informaçóes fomente decisóes clínicas e terapêuticas, capazes de promover continuidade e efetividade do cuidado em saúde ${ }^{4}$. Nessa perspectiva, destaca-se o papel central do agente penitenciário como interlocutor das informaçóes, por acompanhar os detentos nos atendimentos externos às UP.

Quanto à continuidade informacional, cabe à equipe reforçar as orientaçóes médicas e condutas prescritas durante $o$ atendimento realizado no serviço especializado em HIV, entretanto, este indicador foi avaliado como regular, tendo como possível explicação a sobrecarga de trabalho nas UP, a escassez identificada acerca dos registros nos prontuários de saúde das PPL e a centralidade de informaçóes nos agentes penitenciários de saúde. Estudo apontou que a continuidade informacional e a comunicação interprofissional ocorrem de forma precária por falta de prontuários informatizados. ${ }^{(11)}$

Em relação ao desempenho das UP na coordenação do cuidado em HIV, o indicador "Questionam a regularidade no uso da TARV" foi melhor avaliado na UP-C em relação à UP-D. Para explicar tal achado, a UP-C oferecia atendimento em período integral e supervisão da tomada de medicamentos aos detentos que procuravam a equipe de saúde, enquanto a UP-D se restringia ao período da tarde e realizava vistorias mensais nas celas para o monitoramento da ingesta medicamentosa. Verifica-se também um maior número de enfermeiros na UP-C, vislumbrando-se um possível papel de liderança deste profissional, cujas competências o qualificam para o reconhecimento e acolhimento das necessidades e demandas de saúde das PPL vivendo com HIV, contribuindo com o manejo oportuno dos casos.

Convém mencionar que as populaçóes das UP acima referidas são distintas pelo sexo, sendo assim, as demandas de saúde são diferenciadas e percebidas de modo distinto pelos sujeitos. Há uma tendência entre as mulheres detentas em tecerem comentários e críticas em relação aos serviços de saúde como a falta de equipe multiprofissional e o descaso no atendimento individual; ${ }^{(23)}$ possuírem autopercepção mais aguçada em relação às próprias necessidades e problemas de saúde, ${ }^{(24)}$ de tal forma que a avaliação da atenção recebida se difere entre os sexos. Além desses aspectos, em alguns contextos, verifica-se a invisibilidade da mulher presa, que acaba por ser negligenciada em relação a aspectos de sua saúde. ${ }^{(25,26)}$

Como possíveis limitaçóes do estudo tem-se o tamanho amostral, que pode ter inviabilizado a identificação de diferenças no desempenho entre as UP quanto às variáveis da coordenação do cuidado, além de possíveis vieses de memória e de informação.

\section{Conclusão}

O desempenho das unidades prisionais não difere em relação à grande parte dos indicadores de coordenação estudados, indicando que todas precisam melhorar o desempenho no que diz respeito ao desenvolvimento de açôes de monitoramento do uso da TARV, informar e discutir resultados dos exames com os detentos e levar para atendimento fora da unidade prisional. A composição do quadro de recursos humanos, o período de atendimento ofertado pelas equipes de saúde prisionais, a adoção de diferentes estratégias para o monitoramento da TARV e o público prisional atendido poderiam explicar tal achado.

\section{Colaborações}

Cadamuro ACGA, Andrade RLP, Lopes LM, Neves LAS e Monroe AA contribuíram para o desenho do 
estudo, discussão dos dados, escrita do artigo e aprovação da versão final do manuscrito enviado. Cadamuro ACGA e Andrade RLP analisaram os dados.

\section{Agradecimentos}

O presente trabalho foi realizado com apoio da Coordenação de Aperfeiçoamento de Pessoal de Nível Superior-Brasil (CAPES) - Código de Financiamento 001. Fundação de Amparo à Pesquisa do Estado de São Paulo (FAPESP), Projeto "Oferta e integração de açôes e serviços de saúde prestados às pessoas que vivem com HIV/aids em situação de privação de liberdade" - Auxílio Regular. Processo 2015/22312-0.

\section{Referências}

1. World Health Organization (WHO). Consolidated guidelines on HIV prevention, diagnosis, treatment and care for key populations, 2016 Update [Internet]. Geneva: WHO; 2017 [cited 2019 Aug. 15]. Available from: https://apps. who.int/iris/bitstream/handle/10665/246200/9789241511124-eng. pdf;jsessionid=0022A75F7F36B86FEABE34C3C339028B? sequence $=1$

2. Albuquerque AC, Silva DM, Rabelo DC, Lucena WA, Lima PC, Coelho MR, et al. Soroprevalência e fatores associados ao Vírus da Imunodeficiência Humana (HIV) e sífilis em presidiários do Estado de Pernambuco, Brasil. Cien Saude Colet. 2014;19(7):2125-32.

3. Brasil. Ministério da Justiça. Departamento Penitenciário Nacional. Levantamento Nacional de Informações Penitenciárias - INFOPEN - junho de 2014 [Internet]. Brasília (DF): Ministério da Saúde; 2014. [citado 2019 Ago 15]. Disponível em: https://www.justica.gov.br/ news/mj-divulgara-novo-relatorio-do-infopen-nesta-terca-feira/ relatorio-depen-versao-web.pdf.

4. Mendes EV. A construção social da Atenção Primária à Saúde [Internet]. Brasília (DF): Organização Pan-Americana da Saúde; 2015. [citado 2019 Dez 10]. Disponível em: https://www.conass.org.br/biblioteca/ pdf/A-CONSTR-SOC-ATEN-PRIM-SAUDE.pdf.

5. Lermen HS, Gil BL, Cúnico SD, Jesus LO. Saúde no cárcere: análise das políticas sociais de saúde voltadas à população prisional brasileira. Physis. 2015;25(3):905-24.

6. Kringos DS, Boerma WG, Hutchinson A, van der Zee J, Groenewegen PP. The breadth of primary care: a systematic literature review of its core dimensions. BMC Health Serv Res. 2010 ;10(1):65.

7. Almeida PF, Medina MG, Fausto MCR, Giovanella L, Bousquat A, Mendonça MH. [Coordination of care and Primary Health Care in the Unified Health System]. Saúde Debate; 2018; 42(1): 244-260. Portuguese.

8. Brasil. Ministério da Saúde. Secretaria de Vigilância em Saúde. Recomendações para terapia anti-retroviral em adultos e adolescentes infectados pelo HIV 2007/2008 [Internet]. Brasília (DF): Ministério da Saúde; 2008. [citado 2019 Dez11]. Disponível em: http://bvsms.saude.gov.br/bvs/publicacoes/recomendacao_ terapia.pdf.
9. São Paulo. Protocolo de Atenção Básica da Saúde nas Unidades Prisionais do Estado de São Paulo. São Paulo: Secretaria de Administração Penitenciária; 2012.

10. Almeida C, Macinko J. Desenvolvimentos de sistemas de saúde: validação de uma metodologia de avaliação rápida das características organizacionais e do desempenho dos serviços de Atenção Básica do Sistema Único De Saúde (SUS) em nível local [Internet]. Brasília: Organização Pan-Americana de Saúde; 2006. [Série Técnica Desenvolvimento de Sistemas e Serviços de Saúde, 10]. [citado 2019 Dez 11]. Disponível em: http://iah.iec.pa.gov. br/iah/fulltext/pc/monografias/ms/pdsss/pdsss-v10.pdf.

11. Bousquat A Giovanella L, Campos EM, Almeida PF, Martins CL, Mota $\mathrm{PH}$, et al. Atenção primária à saúde e coordenação do cuidado nas regiões de saúde: perspectiva de gestores e usuários. Cien Saude Colet. 2017;22(4):1141-54.

12. Joint United Nations Programme on HIV/AIDS (UNAIDS). 90-90-90: on the right track towards the global target [Internet]. Geneva: UNAIDS; c2014 [cited 2019 Dec 11]. Available from: https://reliefweb.int/sites/ reliefweb.int/files/resources/90_90_90_Progress_ReportFINAL.pdf

13. Davies NE, Karstaedt AS. Antiretroviral outcomes in South African prisoners: a retrospective cohortanalysis. PLoS One. 2012;7(3):e33309.

14. Cunningham WE, Nance RM, Golin CE, Flynn P, Knight K, Beckwith CG, et al. Self-reported antiretroviral therapy adherence and viral load in criminal justice-involved populations. BMC Infect Dis. 2019;19(1):913.

15. Monarca R, Madeddu G, Ranieri R, Carbonara S, Leo G, Sardo M, et al.; SIMSPe-SIMIT Group. HIV treatment and care among Italian inmates: a one-month point survey. BMC Infect Dis. 2015;15(1):562.

16. Sgarbi RV, Carbone AS, Paião DS, Lemos EF, Simionatto S, Puga MA, et al. A cross-sectional survey of HIV testing and prevalence in twelve Brazilian correctional facilities. PLoS One. 2015 ;10(10):e0139487.

17. Edge CL, King EJ, Dolan K, McKee M. Prisoners co-infected with tuberculosis and HIV: a systematic review. J Int AIDS Soc. 2016;19(1):20960.

18. Abiona T, Balogun J, Adefuye A, Anguh I. Anguh. Understanding HIV risk behaviors in prison: a qualitative study among recently released inmates. Int J Prison Health. 2015;11(4):196-208.

19. Fernandes LH, Alvarenga CW, Santos LL, Pazin Filho A. The need to improve health care in prisons. Rev Saude Publica. 2014;48(2):275-83.

20. Silva M. Saúde penitenciária no Brasil: plano e política. Brasília (DF): Verbena; 2015.

21. Wickersham JA, Marcus R, Kamarulzaman A, Zahari MM, Altice $\mathrm{FL}$. Implementing methadone maintenance treatment in prisons in Malaysia. Bull World Health Organ. 2013;91(2):124-9.

22. Fu JJ, Bazazi AR, Altice FL, Mohamed MN, Kamarulzaman A. Absence of antiretroviral therapy and other risk factors for morbidity and mortality in Malaysian compulsory drug detention and rehabilitation centers. PLoS One . 2012; 7:e44249.

23. Minayo MC, Constantino P. Deserdados sociais: condições de vida e saúde dos presos do estado do Rio de Janeiro. Rio de Janeiro: Fiocruz; 2015.

24. Barata RB. Como e porque as desigualdades sociais fazem mal à saúde. Rio de Janeiro: Editora Fiocruz; 2009. Relações de gênero e saúde: desigualdade ou discriminação? p. 73-94.

25. Avais MA, Wassan AA. Female inmates: a neglected population in medical policies of Pakistan. JUMDC. 2017;8(2):34-9.

26. Dixey R, Nyambe S, Foster S, Woodall J, Baybutt M. Health promoting prisons: an impossibility for women prisoners in Africa? Agenda. 2015;29(4):95-102. 